2. ARTIGOS 


\section{ARTIGO N¹}

POR UMA INFRAESTRUTURA LUMINOSA SUSTENTÁVEL NO TERRITÓRIO PAULISTA: UMA ANÁLISE AO LONGO DA ESTRADA DOS ROMEIROS FOR A SUSTAINABLE LIGHT INFRASTRUCTURE IN SÃO PAULO STATE: AN ANALYSIS ALONG THE ESTRADA DOS ROMEIROS

RITA MIER 


\title{
POR UMA INFRAESTRUTURA LUMINOSA SUSTENTÁVEL NO TERRITÓRIO PAULISTA: UMA ANÁLISE AO LONGO DA ESTRADA DOS ROMEIROS
}

\author{
RITA MIER* \\ * Arquiteta graduada (2008) e mestre (2011) pela Faculdade de Arquitetura da \\ Universidade do Porto - FAUP, com intercâmbio (2006) na FAU-UFRJ, Rio de Janeiro. \\ Atualmente doutoranda na área de Tecnologia da Arquitetura pela FAU-USP, investigando sobre \\ o tema da iluminação artificial no espaço urbano. \\ ritamier@usp.br
}

\section{RESUMO}

Nas últimas décadas, as sociedades urbanas vêm aumentando consideravelmente os níveis de luminância no período noturno, diminuindo o contacto com a escuridão. Ora, se nalguns locais a iluminação artificial representa uma necessidade inevitável, já noutras situações - como áreas de preservação ambiental - aquela fonte de energia deve ser minuciosamente implementada. Porém, nem sempre a sua aplicação apresenta padrões estéticos, de eficiência e sustentabilidade que respeitem o ser humano, o meio ambiente e o património edificado.

Assim, o presente artigo começa por explorar o tema da iluminação artificial sob o prisma de questões pertinentes nas atuais sociedades urbanas. Em seguida, apresentase uma breve contextualização histórica dos primórdios da iluminação pública na cidade de São Paulo e consequente expansão para o interior do estado. Este reconheceu destacado desenvolvimento no início de século $X X$, com a indústria cafeeira, que consequentemente despoletou a construção de vias férreas e centrais hidroelétricas. O progresso da iluminação elétrica também surgiu na época, porém, o seu desenvolvimento não conseguiu acompanhar a célere expansão urbana e demográfica que desde então não cessou.

Através de uma observação noturna, elegeu-se como objeto de estudo a antiga Estrada dos Romeiros e quatro cidades do interior do Estado de São Paulo - Santana de Parnaíba, Pirapora do Bom Jesus, Cabreúva e Itú - unidas por aquela via e pertencentes a dois roteiros turísticos: o Caminho do Sol e o Roteiro dos Bandeirantes. Partindo da visão satélite, à macro escala, até à análise aproximada in loco dos referidos meios urbanos e percurso de união, o estudo caracteriza o estado da respetiva iluminação 
pública e principais falhas que hoje se verificam neste setor territorial, representativo do interior paulista. Em termos conclusivos, são propostas medidas que certamente representariam um avanço económico, social, ambiental e cultural para o atual estado da iluminação pública nestas cidades e em geral.

Palavras-chave: Iluminação pública; Luz artificial; Poluição luminosa; Eficiência Energética; Segurança; Património histórico; Plano Diretor de lluminação.

\title{
FOR A SUSTAINABLE LIGHT INFRASTRUCTURE IN SÃO PAULO STATE: AN ANALYSIS ALONG THE ESTRADA DOS ROMEIROS
}

\begin{abstract}
During recent decades, urban societies have been considerably increasing luminance levels at night, diminishing the darkness period. So, if in some places artificial lighting is an inevitable need, other situations - such as environmental preservation areas - that source of energy must be detailed implemented. However, its application does not present always aesthetic, efficiency and sustainability standards that respect the human being, environment and built heritage.
\end{abstract}

Thus, this article begins by exploring the theme of artificial light focusing the relevant issues in current urban societies. Then, it is presented a brief historical overview of the beginnings of street lighting in the São Paulo City and subsequent expansion into the State of São Paulo countryside. That region recognized significant development in the early 20th century with the coffee industry, which unleashed consequently the construction of railways and hydroelectric power plants. The progress of electric lighting also appeared at the time but its development could not follow the rapid urban and demographic expansions which have not stopped since then.

By a night observation, it was elected as object of study of the ancient Estrada dos Romeiros ${ }^{1}$ (Pilgrim's Road) and four cities of São Paulo State countryside - Santana de Parnaíba, Pirapora do Bom Jesus, Cabreúva and Itú - which are linked by

\footnotetext{
${ }^{1}$ The road is so named because it is a traditional pilgrimage route of pilgrims coming from São Paulo City and the Countryside to Pirapora do Bom Jesus, usually by horses, buggies or carts.
} 
that route and belong to two touristic itineraries: Caminho do Sol (Sun Path) and Roteiro dos Bandeirantes ${ }^{2}$ (Bandeirantes' Route). Starting from the satellite view, the macro scale, up to the approximate "in situ" analysis of mentioned urban sites and routes of union, this article characterizes the situation of the corresponding public lighting and main deficiencies existing nowadays at that region of São Paulo State countryside.

Concluding, it is proposed measures which certainly would represent an economic, social, environmental and cultural progress for the current situation of street lighting in those cities and others.

Keywords: Public Lighting; Artificial Light; Light Pollution; Energy Efficiency; Security; Historic Heritage; Lighting Master Plan.

\section{ILUMINAÇÃO URBANA: PERIGOS E PROGRESSOS NA ERA ATUAL}

"Depuis ces toutes premières ambiances lumineuses créées par l'homme lorsqu'il s'installe seul ou en groupe autour du feu, la lumière artificielle est utilisée pour voir, organiser l'espace, décorer, impressionner, transfigurer." 3

O poder e fascínio da iluminação artificial não deixam de surpreender o Homem desde a sua invenção. Nos dias atuais, em que o ser humano tem vindo progressivamente a estender as suas atividades laborais e de lazer para o período noturno, a iluminação artificial ganha cada vez mais importância e notabilidade. Em paralelo, o aumento do sentimento de insegurança que afeta a consciência coletiva, origina a necessidade de se iluminar cada vez mais espaços, à noite.

Se no passado apenas se procuravam atender critérios de funcionalidade e segurança, atualmente a iluminação urbana conquistou a capacidade de valorizar a geografia, as linhas estruturantes e os pontos-chave de uma cidade.

\footnotetext{
${ }^{2}$ Bandeirantes were the members of colonial exploratory expeditions.

${ }^{3}$ NARBONI, Roger, Lumière et ambiances: concevoir des éclairages pour l'architecture et la ville, Le Moniteur, Paris, 2006, p.12
} 
Encarada como um instrumento de composição do espaço público e de organização espacial, a luz é capaz de conferir novas leituras ou mesmo reinventar por completo a perceção urbana do espaço, na sua face noturna.

Mas devido a este seu forte poder de transfiguração, a luz artificial deve ser tratada sabia e cautelosamente, o que ainda se verifica em poucas cidades mundiais, como afirma Roger Narboni:

"The manner in wish the light is emitted, the play and quality of shadows created, contrasts, nocturnal effects, filters, and the accenting of materials, appears to be totally ignored." ${ }^{4}$

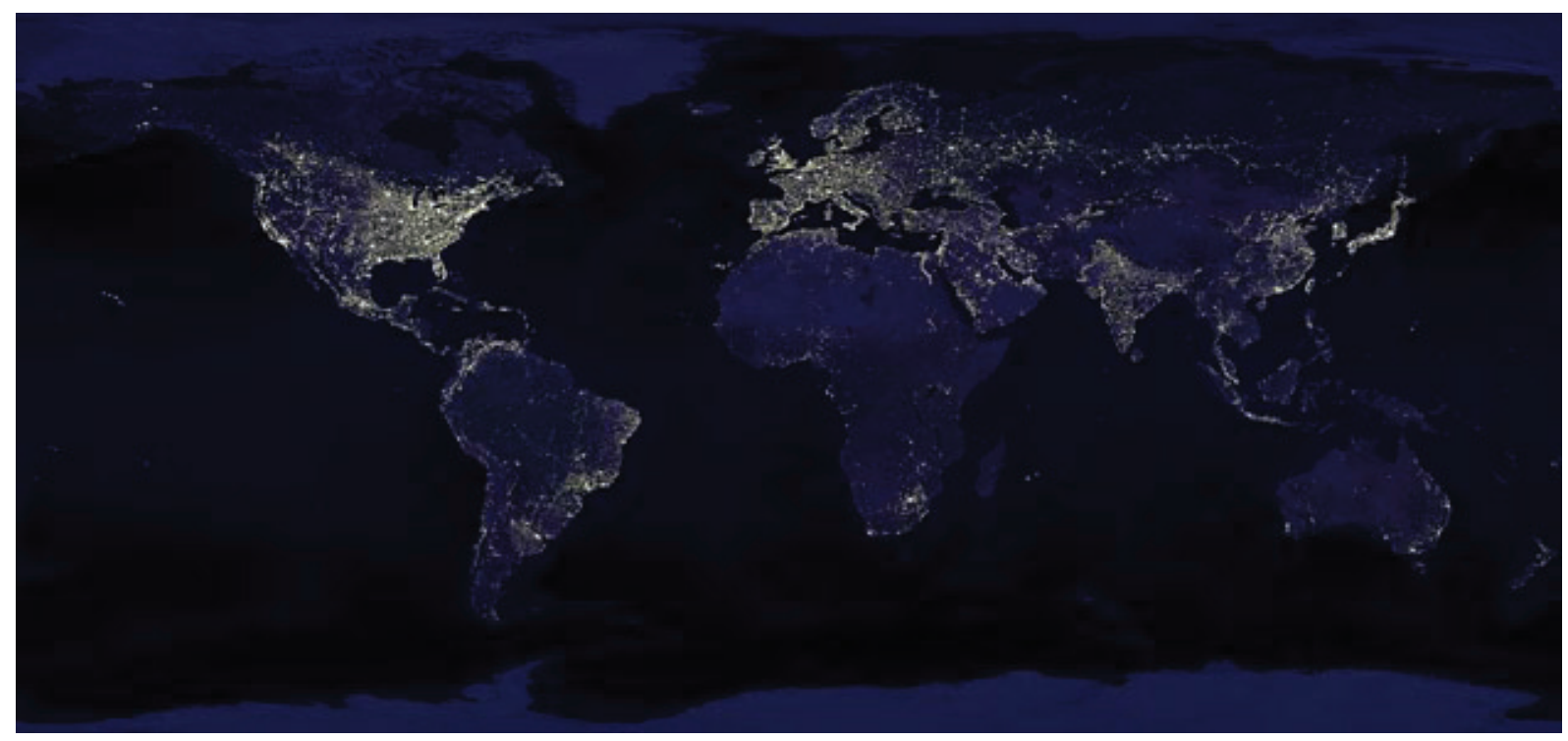

Figura 1: Visão satélite noturna da Terra em 2012: o contraste entre as regiões com e sem energia elétrica. Fonte: https://earthbuilder.google.com/10446176163891957399-13737975182519107424-4/mapview/

A Figura 1 evidencia claramente que "um bilhão e meio (de pessoas) não têm eletricidade; elas habitam os vastos espaços escuros nas fotos da Terra tiradas por satélites à noite." 5

Em contraste com as áreas sem acesso à eletricidade, as regiões urbanizadas apresentam hoje um rosto noturno carregado de luz.

Considera-se que "até 2030, o número de pessoas vivendo em cidades em todo o

\footnotetext{
${ }^{4}$ NARBONI, Roger, Lighting the Landscape: Art, Design, Technologies. Birkhauser, Boston, 2004, p.32.

${ }^{5}$ LOVINS, Amory B. e Rocky Mountain Instltúte, Reinventando o Fogo. Soluções ousadas de negócios na era da energia", Editora Cultrix, São Paulo, 2013, Prefácio XVII.
} 
mundo deverá ultrapassar cinco bilhões. Em 2050, estima-se que os centros urbanos sejam compostos por um total de $70 \%$ da população global." ${ }^{6}$

Estando a população mundial em permanente crescimento e as cidades tornandose mais populosas, se nada for evitado, o mapa terrestre futuro traduzirá claramente essa realidade, com um cada vez maior número de pontos luminosos, aumentando a poluição luminosa nos centros urbanos.

De forma consciente, foram os astronautas os que primeiro alertaram para os efeitos nocivos deste fenómeno, mas hoje várias entidades e mesmo a sociedade civil começam a preocupar-se com as suas nocivas consequências.

A poluição luminosa consiste na expressão que designa a degradação do ambiente noturno devido à emissão de luz artificial que impacta sobre os ecossistemas da fauna e flora e sobre a saúde humana.

Agindo de forma ascendente direta (luz emitida diretamente pelo luminária em direção ao céu) ou de forma ascendente indireta (luz refletida pela superfície iluminada), a poluição luminosa pode ser classificada segundo três formas: halo luminoso, luz ofuscante ou luz intrusa. O primeiro fenómeno é "causado pela luz emitida para cima que ilumina o céu ao ser refletida por partículas em suspensão no ar (poeiras, partículas de agua, etc.) (...) diminui o contraste entre as estrelas e o fundo negro do céu, o que torna difíceis as observações panorâmicas, até impossíveis." $\mathrm{A}$ luz ofuscante, por sua vez, resulta do contraste entre uma fonte de luz intensa e a sua envolvente sombria. A luz intrusa, por fim, é caracterizada pela luminosidade que penetra num espaço onde ela é indesejada (interior de quartos de hotéis, residências privadas, etc.).
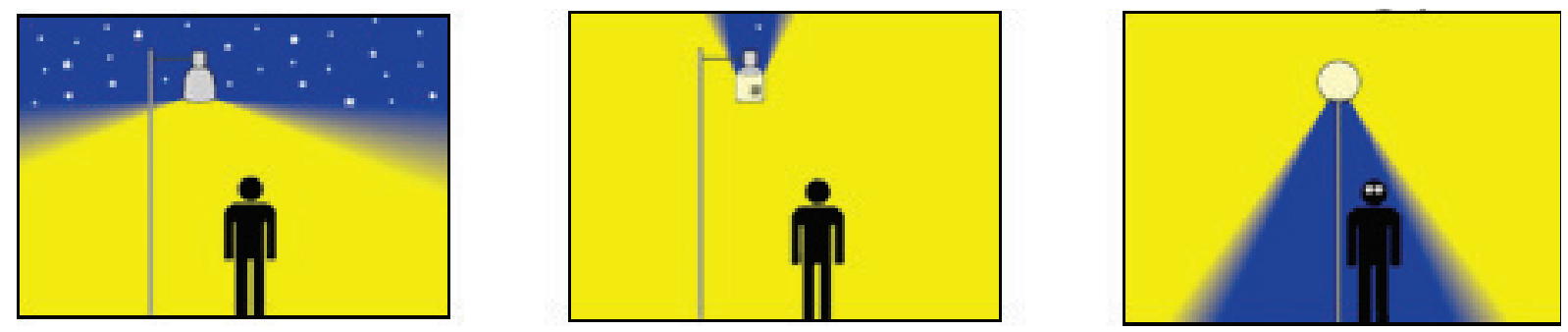

Figura 2: Exemplo de solução boa, má e péssima na iluminação pública. Fonte: http://mcdonaldobservatory. org/darkskies

\footnotetext{
${ }^{6}$ PHILIPS LIGHTING, "Why the world needs more light", 07.10 .13 in http://www.psfk.com/2013/10/worldneeds-light-future-light.html

${ }^{7}$ BOGAERT, Jean Charles, "A luz, nova fonte de poluição", in Revista do Grupo Schréder, n 31, Lisboa, 2005, p.4
} 
Para os seres vivos, as consequências da poluição luminosa são diversas, destacando-se fatores como perturbações a nível da saúde e conforto dos seres humanos (perturbações de sono, alterações fisiológicas do biorritmo), falta de segurança civil e rodoviária (ofuscamento, fadiga da visão, distração do motorista), alterações nos ecossistemas e na biodiversidade animal (morte de insetos atraídos pela luz, alteração de rotas migratórias de aves, perturbação para predadores noturnos, alteração na produção melatonina) e vegetal (adulteração de processos de fotossíntese). De realçar, igualmente, os desperdícios financeiros associados a este fenómeno.

Segundo a AIE (Agência Internacional de Energia), "19\% da necessidade mundial de eletricidade diz respeito à iluminação", ${ }^{8}$ pelo que o seu desperdício deve ser urgentemente evitado. $O$ excesso de consumo energético e as mudanças climáticas mundiais são temas de extrema atualidade e preocupação, nos quais a iluminação artificial desempenha um papel preponderante.

De ressaltar algumas atitudes e soluções que têm surgido, no sentido de combater o referido fenómeno.

Por um lado, o progresso do saber científico e da evolução tecnológica nos surpreendem diariamente com o aumento da eficiência dos equipamentos e otimização e variedade de fontes de iluminação. Note-se o aperfeiçoamento exponencial da tecnologia LED, de muito baixo consumo e longa durabilidade, dos sistemas óticos das luminárias, do rendimento dos diferentes tipos de equipamento ou dos processos de automação e gestão centralizada.

Por outro lado, tem sido dada uma cada vez maior importância às questões da sustentabilidade e da racionalização dos consumos energéticos, fatores imperativos em qualquer projeto consciente do século XXI. Sendo a produção de energia significativamente poluente na sua emissão de $\mathrm{CO}^{2}$, torna-se fundamental, neste novo século, atuar na redução dos consumos elétricos e promover o aumento da eficiência das soluções adotadas nas intervenções arquitetónicas e urbanísticas.

O tema da segurança é igualmente indissociável do da iluminação pública e, cada vez mais, se denota a consciencialização para esta questão. Em termos de segurança viária, a

\footnotetext{
${ }^{8}$ ANPCEN (Association Nationale pour la Protection du Ciel et de l'Environnement Nocturnes), "Dossier : La pollution Lumineuse", 01.08.07, p. 11, in www.jourdelanuit.fr/IMG/pdf/Dossier_ANPCEN_poll_lumineuse-2.pdf
} 
aplicação da luz artificial é determinante para o aumento ou diminuição da visibilidade dos condutores. Já para os pedestres, embora a iluminação não resolva por completo o problema da criminalidade, é sem dúvida um fator dissuasivo e de prevenção. Afinal, "a escuridão favorece o ataque-surpresa, dificulta a identificação do criminoso e facilita a fuga." $\mathrm{De}$ referir, porém, que a solução não deverá passar por inundar todos as áreas públicas com quantidades excessivas de luz, pois um espaço invadido por uma luz totalitária que destrói a diferença e nega qualquer poética, certamente não será um espaço que nos transmita emoção e bem-estar. Neste domínio, revela-se portanto crucial a compreensão do poder da luz, mas também da sombra, pois "não iluminar é tão importante como iluminar". ${ }^{10}$

"Darkness is not something to be dispelled forever by light. It is not the enemy of light, but rather its friendly counterpart. (...) Through the interaction of both, space and form became visual realities." 11

Para além da pertinência das questões acima referidas, mas não menos importante, há que refletir sobre a capacidade de valorização urbana e cultural que a iluminação do espaço público atualmente detém, não fosse a luz "promotora, apreciadora, percursora da nossa cultura." 12

O processo criativo, munido de sensibilidade artística e emocional, deve ser indissociável de qualquer projeto de iluminação urbano, pois constitui uma componente decisiva para a qualidade do resultado final. A luz é incrivelmente capaz de embelezar e ordenar a paisagem e os espaços do Homem e, sendo o modo como as pessoas irão ocupar o espaço projetado uma das maiores preocupações do arquiteto, a iluminação tornou-se num dos principais instrumentos à sua disposição para humanizar o espaço construído ou para decifrar o lado noturno das cidades.

“De nos jours, l'éclairage n'est plus considéré comme un équipement, choisi sur catalogue puis installé, mais comme un véritable aménagement, partie intégrante du projet urbain." 13

\footnotetext{
9 SILVA, José Vicente da (consultor em segurança pública), entrevistado para artigo "Sem luz no fim do túnel", in revista Veja São Paulo, Ano 46, n 29, 17.07.13, Editora Abril, São Paulo, p.48.

${ }^{10}$ GASPER, Peter, "Pensar a Luz", Conferência na Faculdade de Arquitetura da Universidade do Porto, 22.04.08.

${ }^{11}$ LARSON, Leslie, Lighting and its design, Whitney Librairy of Design, Nova lorque, 1964, p.6

${ }^{12}$ Idem, p.146.

${ }^{13}$ NARBONI, Roger, "Brève histoire de l'urbanisme lumière", in Penser la ville par la lumière, direcção de MASBOUNGI, Ariella, Éditions de la Villette, Paris, 2003, p.22
} 
Com a valorização histórica e cultural de monumentos e outros edifícios ou espaços de referência através da luz artificial, as cidades aumentam o seu potencial turístico e, consequentemente, económico.

\section{ILUMINAÇÃO PÚBLICA NO ESTADO DE SÃO PAULO}

Desde a segunda metade do século XIX, os lampiões com querosene e posteriormente a gás eram a principal forma de iluminar ruas e praças paulistas. Porém, a partir de início do século $X X$, a implementação de luz elétrica passou a ser uma realidade. A eletricidade veio progressivamente sobrepor-se à anterior fonte de luz, "até que em 1937, apaga-se o último lampião a gás de São Paulo."14

Assim, o processo de implementação de luz elétrica inicia-se em 1905, em que "são instaladas as primeiras lâmpadas elétricas da cidade - na rua Barão de Itapetininga - contratadas com a The São Paulo Tramway, Light and Power Company Ltda", ${ }^{15}$ embora só durante a década seguinte o processo se tenha verdadeiramente expandido.
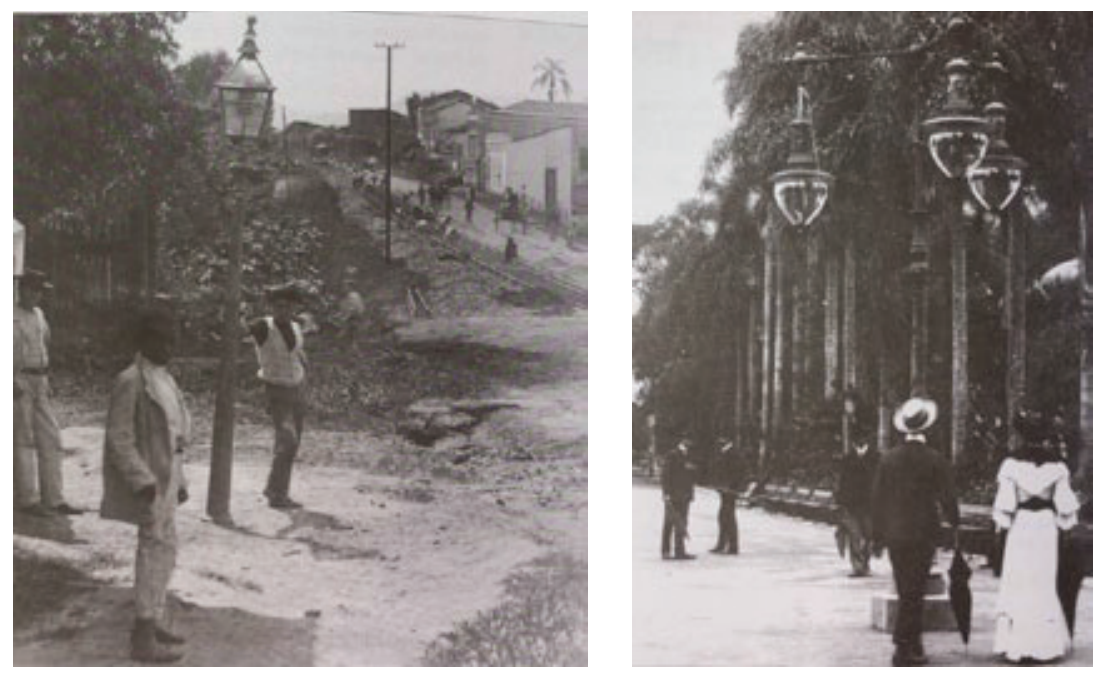

Figuras 3 e 4: lluminação pública a gás em 1904 (esq.) e elétrica em 1908 (dir.), em São Paulo. Fonte: SHIAVO, Rita de Cássia Martinez lo (Coordenação), Fontes para a História da lluminação Pública da Cidade de São Paulo.1899-1917, Série Instrumentos de Pesquisa, Eletropaulo - Departamento de Património Histórico, São Paulo, 1996, p. 30 e 58.

\footnotetext{
${ }^{14}$ SHIAVO, Rita de Cássia Martinez lo (Coordenação), Fontes para a História da lluminação Pública da Cidade de São Paulo.1899-1917, Série Instrumentos de Pesquisa, Eletropaulo - Departamento de Património Histórico, São Paulo, 1996, p.9

15 "História da lluminação" in www.prefeltúra.sp.gov.br/cidade/secretarias/servicos/ilume/missao/index. php?p=312
} 
Em São Paulo, "a rede de iluminação pública implantada sobretudo de 1911 em diante e sua subsequente expansão, teria papel importante na orientação do crescimento urbano da cidade." 16

Este crescimento já se havia começado a verificar no final do século XIX, sobretudo a partir das décadas de 1880/90, em que a cidade e o estado de São Paulo conheceram profundas transformações económicas, sociais, administrativas e urbanas.

Com efeito, "os fatores conjugados dos lucros da produção de café, a localização geográfica, a ferrovia, o início da imigração, o movimento das gentes, dos produtos e de capitais que circulam por esta cidade irão levá-la a assumir, cada vez mais acentuadamente, o papel de entroncamento de caminhos." ${ }^{17}$

A expansão da produção e comércio de café e o investimento de capitais internacionais ${ }^{18}$ foram dos principais impulsionadores deste processo que se traduziu no aparecimento de novas ferrovias, indústrias e fornecimento de energia elétrica para espaços públicos e privados no estado de São Paulo.

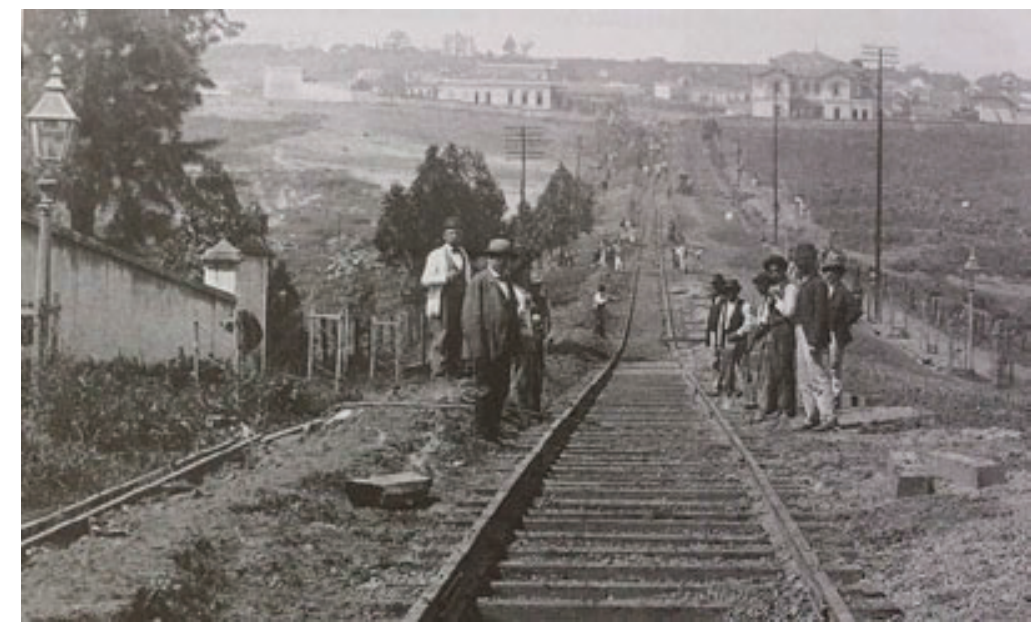

Figura 5: Avenida Brigadeiro Luiz António em 1890: a expansão urbana e tecnológica traduzida na criação de linhas férreas. Fonte: SHIAVO, Rita de Cássia Martinez lo (Coordenação), Fontes para a História da lluminação Pública da Cidade de São Paulo.1899-1917, Série Instrumentos de Pesquisa, Eletropaulo - Departamento de Património Histórico, São Paulo, 1996, p.16

\footnotetext{
${ }^{16}$ ELETROPAULO, A Cidade da Light - 1899-1930: edição bilingue português-inglês comemorativa dos 5.000.000 de ligações / The City of the Light Company - 1899-1930: bilingual edition portugueseenglish 5.000.000 consumers commemorative /, Vol. I, Eletropaulo, São Paulo, 1990, p.14.

${ }^{17}$ ELETROPAULO - Eletricidade de São Paulo. Superintendência de Comunicação. Departamento de Patrimônio Histórico, Evolução Urbana da Cidade de São Paulo. 1872-1945. Série Bibliografia 1, Eletropaulo, São Paulo, 1990, p.11

${ }^{18}$ ELETROPAULO, A Cidade da Light - 1899-1930: edição bilingue portaguês-inglês comemorativa dos 5.000.000 de ligações / The City of the Light Company - 1899-1930: bilingual edition portuguese-english 5.000.000 consumers commemorative /, Vol. I, Eletropaulo, São Paulo, 1990, p.12.
} 
O interior do estado, até então maioritariamente agrícola, iniciava assim o seu processo de industrialização e de evolução da rede de iluminação pública.

Inaugurada em 1901, a central hidrelétrica da Light em Parnaíba foi prova disso, tendo permitido à companhia "estender as suas linhas de bondes, iniciar o fornecimento de força às indústrias e ganhar a concessão da iluminação de ruas e residências."19 A cidade de Itú, por exemplo, testemunhou em 1906 "a primeira experiência da iluminação pública promovida pela Companhia Força e Luz", ${ }^{20}$ deslumbrando os seus cidadãos. Já a Usina do Rasgão, inaugurada em 1924 no Rio Tietê, entre Santana de Parnaíba e Cabreúva, representou um importante fator de industrialização da região.

Curiosamente, no momento das primeiras manifestações de iluminação pública em São Paulo, em que "todos aplaudiam, sem exceção, as conquistas estéticas e morais possibilitadas pela energia elétrica”, ${ }^{21}$ alguns 'iluminados' pareciam já antever o que se viria a tornar numa preocupação da era atual. Isto porque "os mais saudosistas chegavam a pedir à Light o desligamento das luzes na madrugada, para melhor apreciar o desenho celeste dos astros, numa atmosfera ainda não tão poluída." ${ }^{22}$

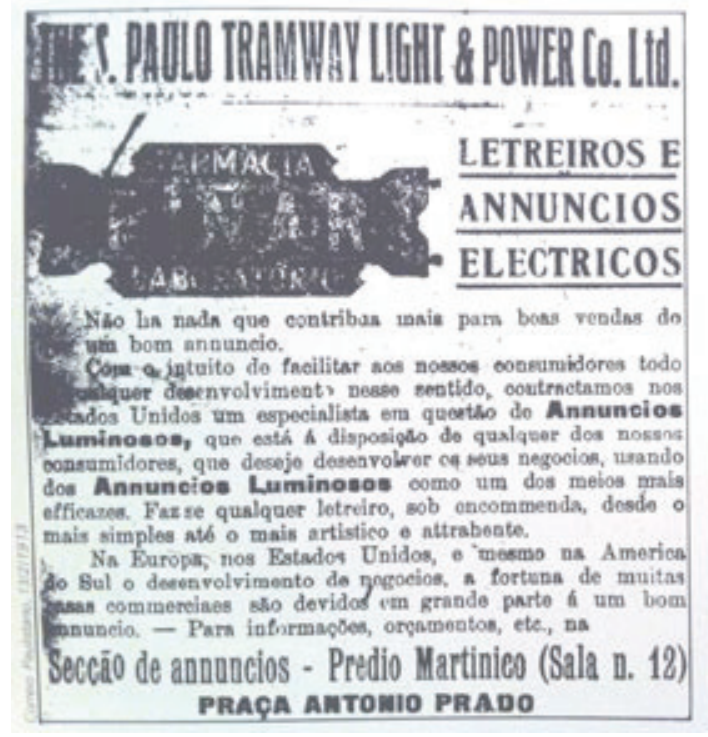

Figura 6: Propaganda a anúncios luminosos em 1913. Fonte: Correio Paulistano, 13/02/1913

\footnotetext{
${ }^{19}$ ELETROPAULO, A Cidade da Light - 1899-1930: edição bilingue português-inglês comemorativa dos 5.000.000 de ligações / The City of the Light Company - 1899-1930: bilingual edition portuguese-english 5.000.000 consumers commemorative /, Vol. II, Eletropaulo, São Paulo, 1990, p.108.

${ }^{20}$ Jornal "Republica”, n 469, Itú, 25 de Janeiro de 1906.

${ }^{21}$ SOUZA; Edgar de, Historia da Light: Primeiros 50 anos, Eletropaulo: Secretaria de Obras e do Meio Ambiente, São Paulo, 1982, p.7

22 Idem, p.7
} 
Com efeito, se há um século atrás, até os primeiros anúncios luminosos eram na capital paulista alvo de grande atração e novidade para a cidade (Figura 6), hoje os efeitos nocivos desta forma de publicidade tornaram-se numa ameaça pela poluição luminosa que originam.

Atualmente, os meios disponíveis de prevenção e correção deste fenómeno são diversos, mas a população e entidades governamentais têm de tomar consciência urgente do problema. O céu e o ambiente noturno devem ser preservados por razões éticas e estéticas e têm de persistir como legado natural para as gerações futuras.
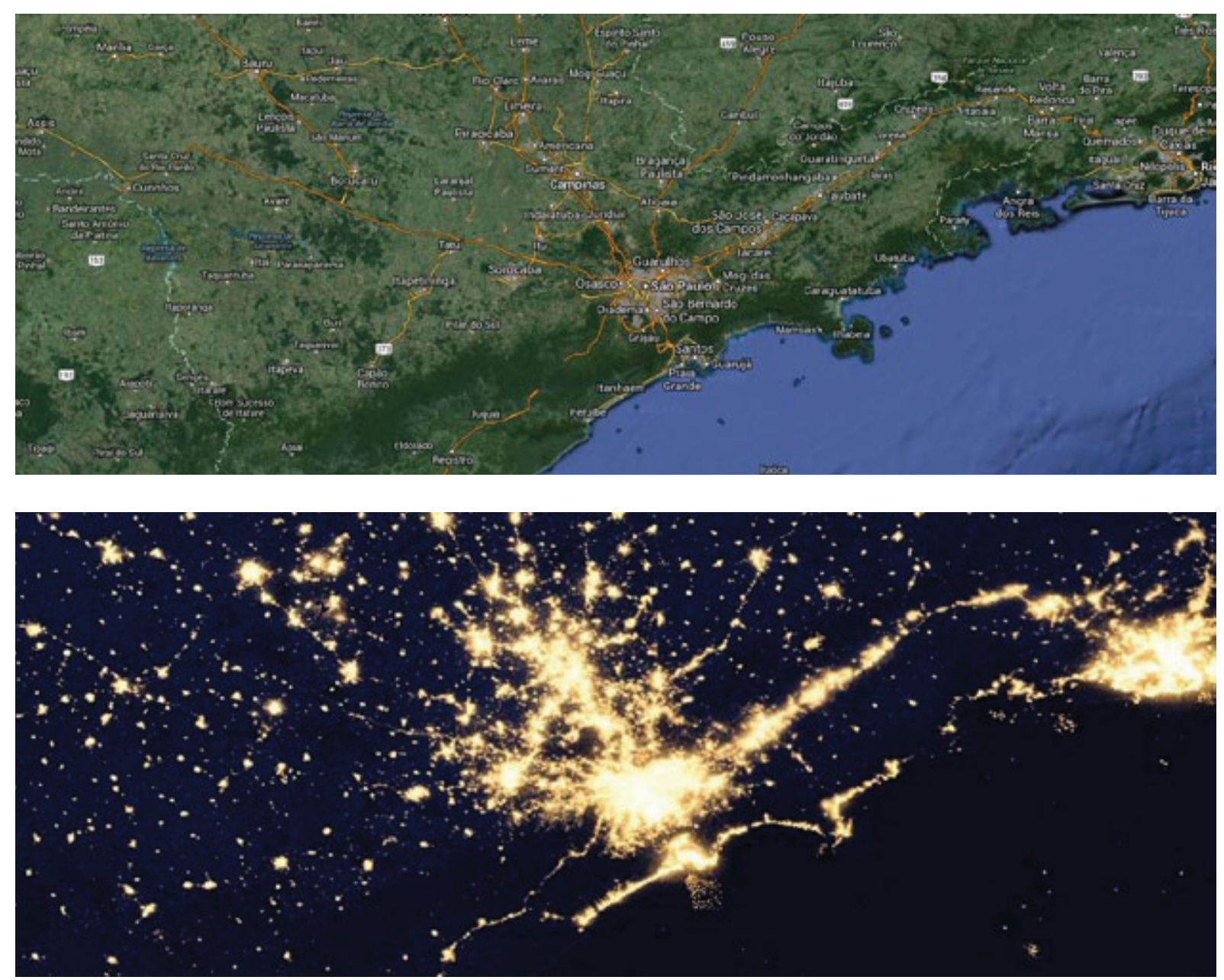

Figuras 7 e 8: Imagens satélite diurna e noturna da região litoral e interior de São Paulo, em 2012. Fonte: https://earthbuilder.google.com/10446176163891957399-13737975182519107424-4/mapview/

Desde o início do século XX, a expansão urbana do estado de São Paulo não cessou então de crescer exponencialmente, o que originou muitos dos seus atuais problemas, reveladores de um crescimento acelerado que não se fez acompanhar de um adequado planejamento urbano. 
Em termos de iluminação pública, este desfasamento é notório, e nas últimas décadas a evolução neste setor tem sido pouco significativa.

Prova disso, é o descontentamento generalizado que a população paulista apresenta no que concerne esta área. De lamentar que "movimentos de reivindicação para meIhoria da iluminação das ruas da cidade e a falta de luz decorrente de fortes chuvas" 23 fossem notícia em 1908 e ainda o sejam, passados mais de cem anos.

Um estudo realizado este ano pela prefeitura de São Paulo revela que "152.000 pontos, ou $30 \%$ do total, produz menos de 10 lux", ${ }^{24}$ nível de iluminância mínimo aceitável para ruas residenciais, havendo "um deficit de 18.000 pontos de luz na capital." 25

Se as estatísticas indicam que o estado de São Paulo apresenta um aumento demográfico e uma expansão urbana exponencial, ${ }^{26}$ e se observarmos no geral o panorama atual da sua iluminação pública, torna-se evidente a necessidade de transformação e evolução que esta área de intervenção demanda.

Sendo a qualidade ambiental do espaço público um requisito basilar para o pleno exercício da cidadania, a iluminação desempenha um papel fulcral no cumprimento deste objetivo.

\section{OBSERVAÇÃO NOTURNA DOS CASOS DE ESTUDO}

\section{Análise geral}

A presente investigação restringiu-se a uma área específica do interior estado de São Paulo, característica pelo seu potencial turístico e ambiental.

\footnotetext{
${ }^{23}$ SHIAVO, Rita de Cássia Martinez lo (Coordenação), Fontes para a História da lluminação Pública da Cidade de São Paulo.1899-1917, Série Instrumentos de Pesquisa, Eletropaulo - Departamento de Património Histórico, São Paulo, 1996, p.59

${ }^{24}$ COLOMBO, Silas, "Sem luz no fim do túnel" in revista Veja São Paulo, Ano 46, n 29, 17.07.13, Editora Abril, S.Paulo, p.47.

${ }^{25}$ Idem, p.48.

${ }^{26}$ Segundo o Instituto Brasileiro de Geografia e Estatística (IBGE), a população estimada para o Estado de São Paulo em 2013 é de 43.663.669 habitantes, mais 2.4010.470 que há três anos atrás. In http://www. ibge.gov.br/estadosat/perfil.php?sigla=sp.
} 
Observando os percursos definidos pelos famosos Roteiro dos Bandeirantes ${ }^{27} \mathrm{e} \mathrm{Ca}-$ minho do Sol, ${ }^{28}$ torna-se possível identificar que o primeiro trecho de ambos os trajetos partilha, em comum, as cidades de Santana de Parnaíba, Pirapora do Bom Jesus, Cabreúva e Itú, todas percorríeis pela antiga Estrada dos Romeiros.

A eleição destas cidades e percurso entre elas prende-se assim com o fato de estarmos perante a concentração de interessantes atributos urbanos e paisagísticos, fortes características históricas, culturais e religiosas e, por consequência, claras potencialidades turísticas.

Embora os referidos roteiros turísticos sejam realizados principalmente no período diurno, por peregrinos e aventureiros, é uma evidência que o turismo noturno tem aumentado e que cada vez mais as cidades são vivenciadas e apreciadas mesmo após o cair da noite..$^{29}$

A iluminação noturna representa, neste prisma, um elemento urbano essencial que detém a capacidade de valorizar a identidade cultural e local de um determinado espaço ou mesmo região. Inversamente, o contexto geocultural também se apresenta determinante para a definição da iluminação do local, o que, lamentavelmente, pouco se verifica nas cidades contemporâneas.

"If there is a professional field where the geocultural factor plays a role, then certainly this would be artificial light. However, as may be easily observed, large-scale lamp manufacturers tend towards uniformity in their products, resulting in a deficit in the range of colors available everywhere." 30

Da amostra territorial que serviu de base ao presente artigo, destacaram-se então duas realidades para análise da sua relação com a iluminação no período noturno: os centros urbanos já referidos e o percurso mais tradicional de transição entre eles.

\footnotetext{
${ }^{27}$ Roteiro dos Bandeirantes: Um dos mais importantes roteiros turísticos de São Paulo, envolvendo as cidades de Santana do Parnaíba, Pirapora do Bom Jesus, Araçariguama, Cabreúva, Salto, Itú, Porto Feliz e Tietê. Viagem pelo traçado por onde passaram os desbravadores que partiram da Vila de São Paulo de Piratininga para o então desconhecido território nacional.

${ }^{28}$ Caminho do Sol: Trajeto de reflexão, onde o peregrino caminha por $240 \mathrm{~km}$ aproximadamente. Passagem pelas cidades de: Santana de Parnaíba, Pirapora do Bom Jesus, Cabreúva, Itú, Salto, Indaiatuba, Elias Fausto, Capivari, Mombuca, Saltinho, Piracicaba, Águas de S.Pedro.

${ }^{29}$ Veja-se, por exemplo, a recente iniciativa "A Lua sobre o Coliseu", uma iniciativa turística da capital italiana que consiste na criação de uma visita guiada noturna, bissemanal, à principal atração da cidade Roma.

${ }^{30}$ NARBONI, Roger, Lighting the Landscape: Art, Design, Technologies. Birkhauser, Boston, 2004, p.32.
} 
Deste modo, unindo as cidades de Santana de Parnaíba, Pirapora do Bom Jesus, Cabreúva e Itú, a Estrada dos Romeiros apresenta-se como uma via antiga, de carácter histórico e, consequentemente com potencial turístico.

\section{lluminação viária na Estrada dos Romeiros}

A denominada Estrada dos Romeiros corresponde a um trecho da "SP-312, a antiga 'Estrada de Itú', aberta em tempos remotos e adaptada ao trânsito de automóveis." 31

Atravessando Áreas de Proteção Ambiental, como a APA de Cabreúva, torna-se compreensível que, em termos de iluminação viária, esta estrada não seja continuamente iluminada por postes, preservando assim o silêncio noturno exigido em áreas com este carácter.

Todavia, tratando-se de um caminho sinuoso com uma única faixa em cada sentido, é possível constatar, hoje, diversas situações que o tornam bastante perigoso. Por exemplo, de destacar a falta de sinalização do pavimento devido a faixas brancas desgastadas e sem eficiência luminescente, a ausência de balizadores e refletores de pavimento, os ofuscamentos pontuais para os condutores devido a luminárias de propriedades privadas mal direcionadas, as lombas de piso não iluminadas, etc.

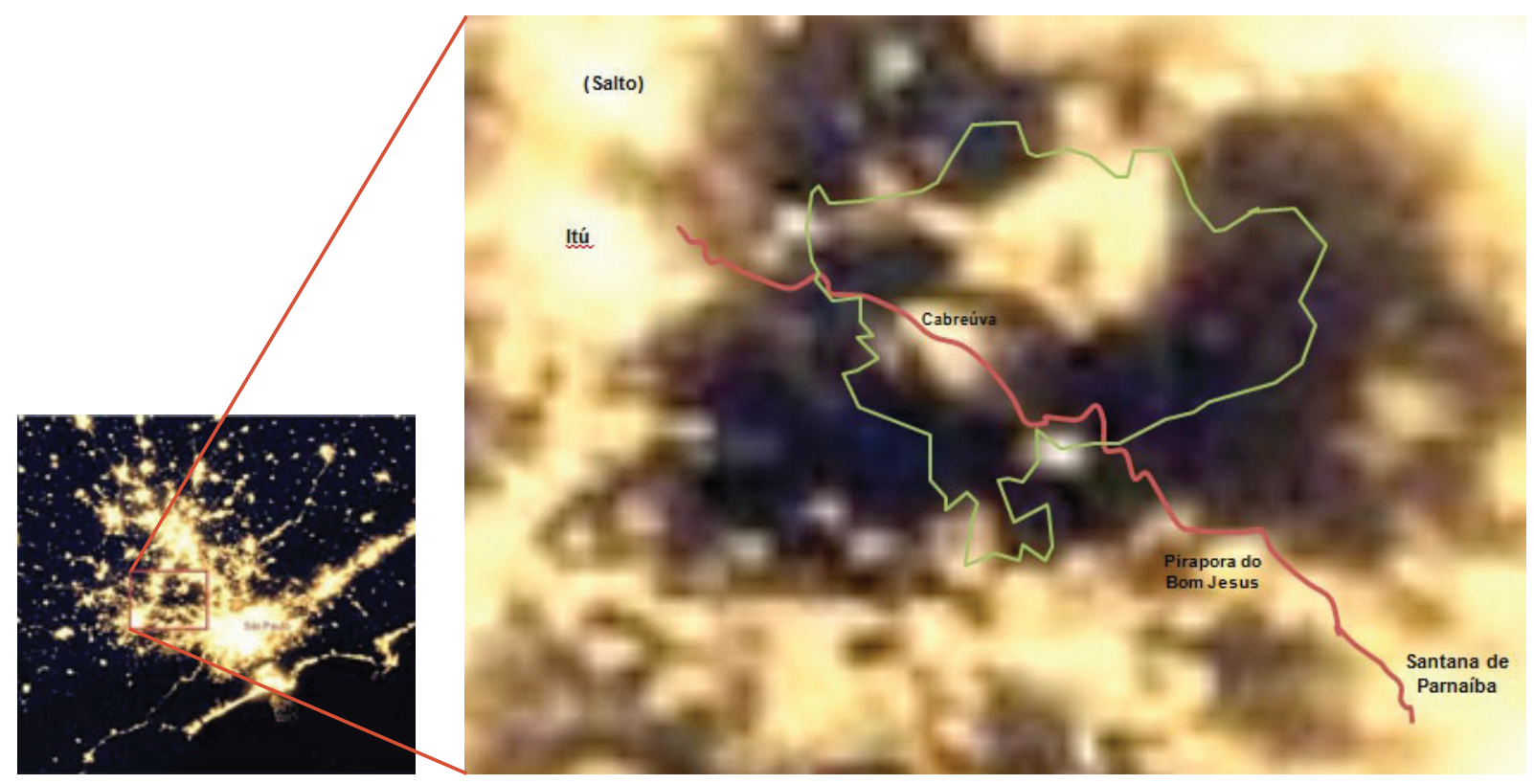

Figura 9: Ampliação da visão satélite noturna das cidades em estudo; delimitação (a verde) da APA Área de Preservação Ambiental - de Cabreúva e Estrada dos Romeiros (a vermelho).

Fonte: https://earthbuilder.google.com/10446176163891957399-13737975182519107424-4/mapview/

${ }^{31}$ http://pt.wikipedia.org/wiki/SP-312 
Observando a Figura 9, onde se destaca a APA de Cabreúva e o percurso da Estrada dos Romeiros, facilmente distinguimos o contraste entre as referidas áreas de total escuridão e o repentino clarão luminoso correspondente aos meios urbanos que esta via interliga.

Nos trechos da estrada onde existe iluminação, ainda fora das cidades, verifica-se que, no geral, os postes e equipamentos de iluminação se encontram em estado obsoleto. Com frequência, avistam-se lâmpadas queimadas, denunciando falta de manutenção e originando má visibilidade ao condutor, pela ausência de homogeneidade na projeção da luz, o que provoca fortes contrastes de luz e sombra ao longo da rodovia. As lâmpadas empregues, a maior parte ainda de vapor de sódio, detêm um baixo IRC (índice de restituição cromática), banhando todo o espaço e paisagem de tonalidade laranja.

Por contraste, aquando da aproximação a um cruzamento ou rotatória de entrada em um centro urbano, o excesso de iluminação, geralmente branca, torna-se extremamente ofuscante para quem acaba de chegar de uma via completamente escura ou com baixos níveis de iluminância. Também para quem sai destes pontos de cruzamento e retoma a estrada, não iluminada, a transição entre as duas realidades lumínicas apresenta-se muito brusca, prejudicando a adaptação da visão do condutor, principalmente se este for de idade mais avançada.

Também os postos de abastecimento, carregados de luminárias contrastando com a envolvente sombria, se tornam pontos de agressivo ofuscamento.

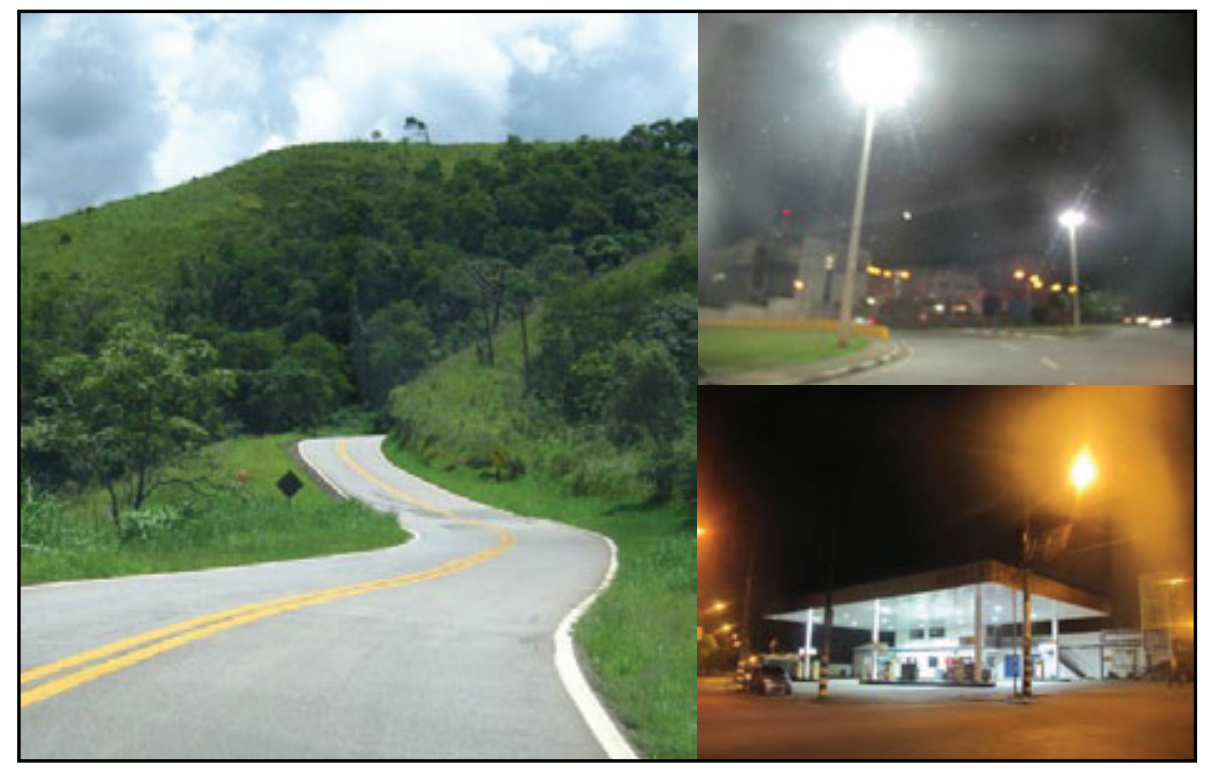

Figura 10 : Estrada dos Romeiros sem postes de iluminação (esq) em contraste com rotatórias e postos de serviço ao longo do seu percurso, com iluminação ofuscante para os condutores (dir). Fonte:

Fotografias da autora 
Um outro problema recorrente, que se deve a características ambientais, corresponde à presença de árvores de grande porte e de folhagem exuberante que com frequência ladeiam a via. A não manutenção e poda das mesmas, associada a uma escolha de equipamento indiferente às características da flora regional, resultam na projeção de inúmeras sombras e redução da projeção de luz no pavimento, o que pode afetar gravemente a visibilidade do condutor.

"As a function of the progressive growth of the vegetation, the illumination will become decreasingly perceptible (...). This transformation must therefore be accurately anticipated within each project, through the position and height of lighting fixtures, the choice of lamp strength, and the angle of reflectors." 32

\section{Iluminação nos centros urbanos em análise}

Concentrando agora a avaliação nas cidades de Santana de Parnaíba, Pirapora do Bom Jesus, Cabreúva e Itú, o enfoque da análise restringiu-se aos centros históricos destes quatro meios urbanos de escalas distintas, por aí ainda se concentrar algum legado patrimonial e espaços públicos urbanisticamente bem definidos.

Porém, no geral, a iluminação noturna dos espaços analisados mais deprecia do que valoriza esses pontos com potencial interesse urbano e turístico.

Esta constatação resulta da quantidade ora insuficiente ora excessiva de iluminação, da negligência de princípios de conforto visual e ofuscamento, do descurar dos índices de restituição cromática e adequadas temperaturas de cor, do ignorar dos efeitos expressivos e de valorização patrimonial, do desprezo pela exigência na qualidade dos equipamentos e/ou ainda da falha por um elevado consumo energético.

Mais concretamente, a observação no período noturno às quatro cidades permitiu identificar aspetos negativos em comum, no que diz respeito à sua iluminação noturna.

Começando pelas praças principais, estas apresentam-se todas iluminadas por luminárias em formato esférico, de iluminação ascensional direta, ou seja, o modelo que mais produz poluição luminosa por emanar luz diretamente para o céu em vez de a concentrar na via, onde realmente é necessária.

\footnotetext{
${ }^{32}$ NARBONI, Roger, Lighting the Landscape: Art, Design, Technologies. Birkhauser, Boston, 2004, p.33.
} 

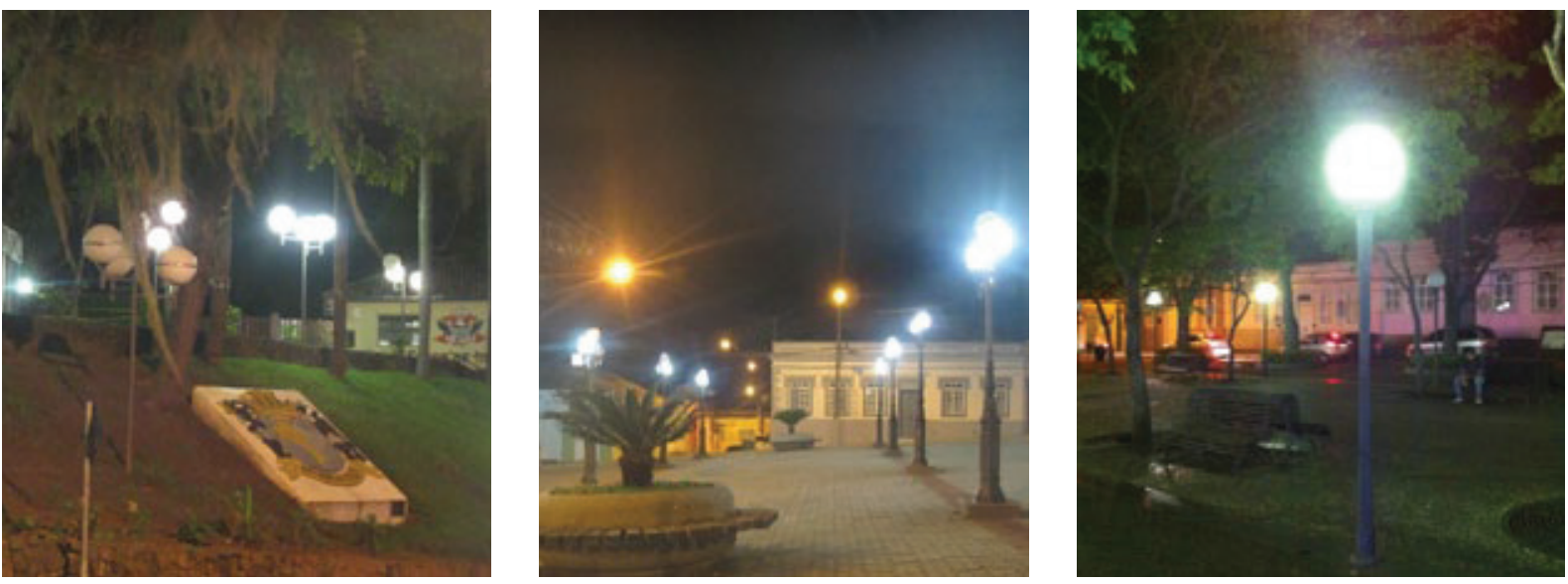

Figuras 11, 12 e 13: Luminárias causadoras de poluição luminosa (halo luminoso) pela emissão de luz ascensional direta, em praças de Santana de Parnaíba, Cabreúva e Itú. Fonte: Fotografias da autora.

Com a recente vulgarização no mercado das lâmpadas compactas fluorescentes (economizadoras), praticamente todas estas praças encontram-se iluminadas com essas lâmpadas na versão com temperatura de cor muito branca, gerando um ambiente frio e desconfortável para o cidadão, que procura nesses locais um espaço aprazível e promotor de bem-estar. Nalguns casos, como no centro histórico de Itú, prevalecem praças com lâmpadas de tonalidades completamente distintas.
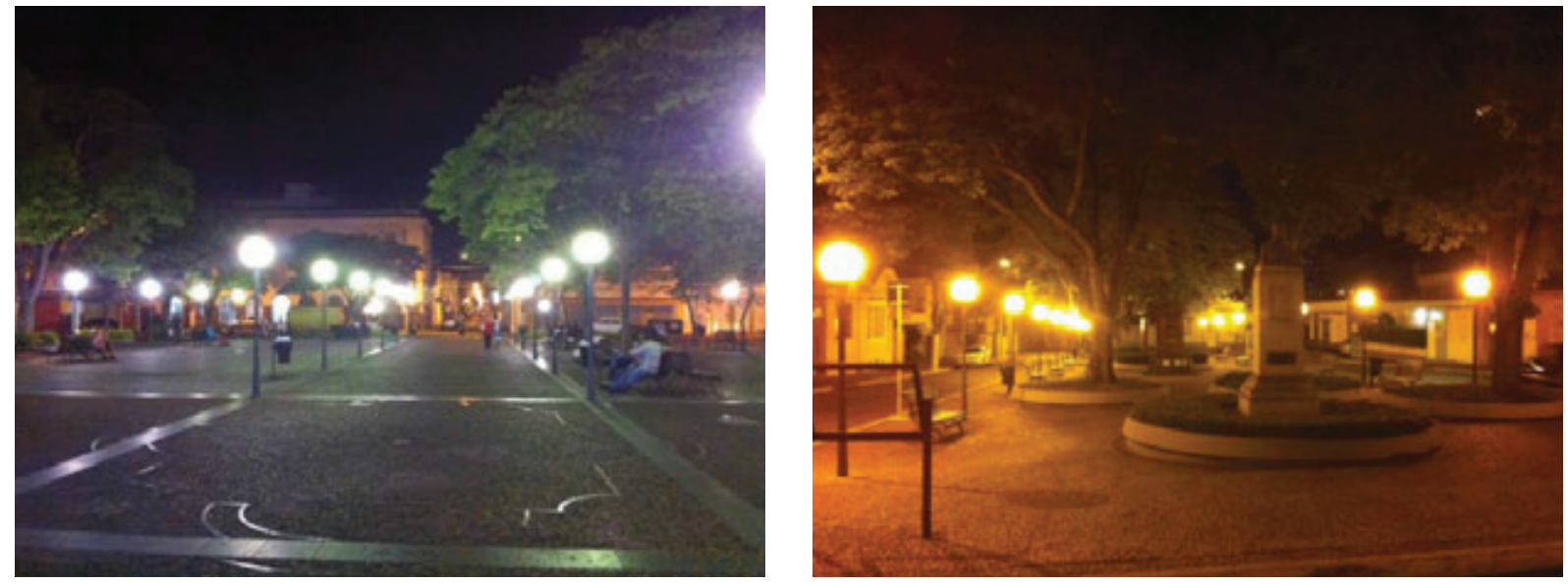

Figuras 14 e 15: Praça da Matriz e Praça Padre Anchieta em Itú: lâmpadas com tonalidades de cor completamente distintas e fenómeno de halo luminoso pelo recurso a luminárias de luz ascensional direta. Fonte: Fotografias da autora.

Em relação ao património histórico existente, representado principalmente pela(s) Igreja(s) e alguns museus das cidades, nalguns casos estes elementos de referência na malha urbana não estão de todo iluminados, retirando qualquer possibilidade de o visitante apreciar a sua arquitetura, após o cair da noite, ou de se aperceber destes pontos-chave que compõe a cidade. 

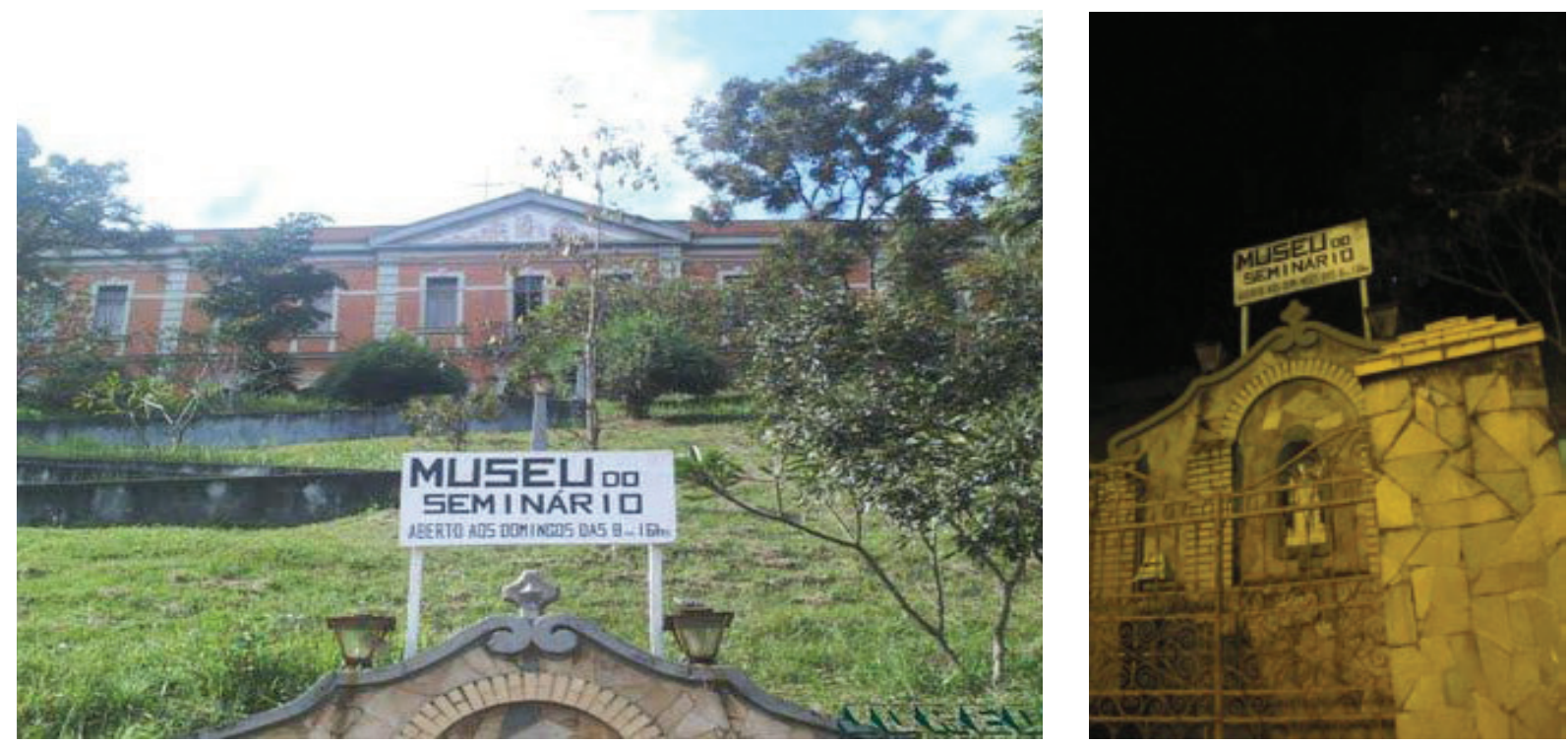

Figuras 16 e 17: Museu do Seminário em Pirapora do Bom Jesus: Um edifício histórico que à noite perde toda a sua referência e hierarquia na malha urbana da cidade pela falta de iluminação. Fonte: Fotografias da autora

Mas quando iluminados, diversos edifícios históricos carecem de um adequado projeto luminotécnico que valorize as suas características formais e preserve, por exemplo, as suas verdadeiras cores, consequência do recurso a lâmpadas com baixos índices de reprodução cromática ou da aprovação de decisões estéticas subjetivas e discutíveis.
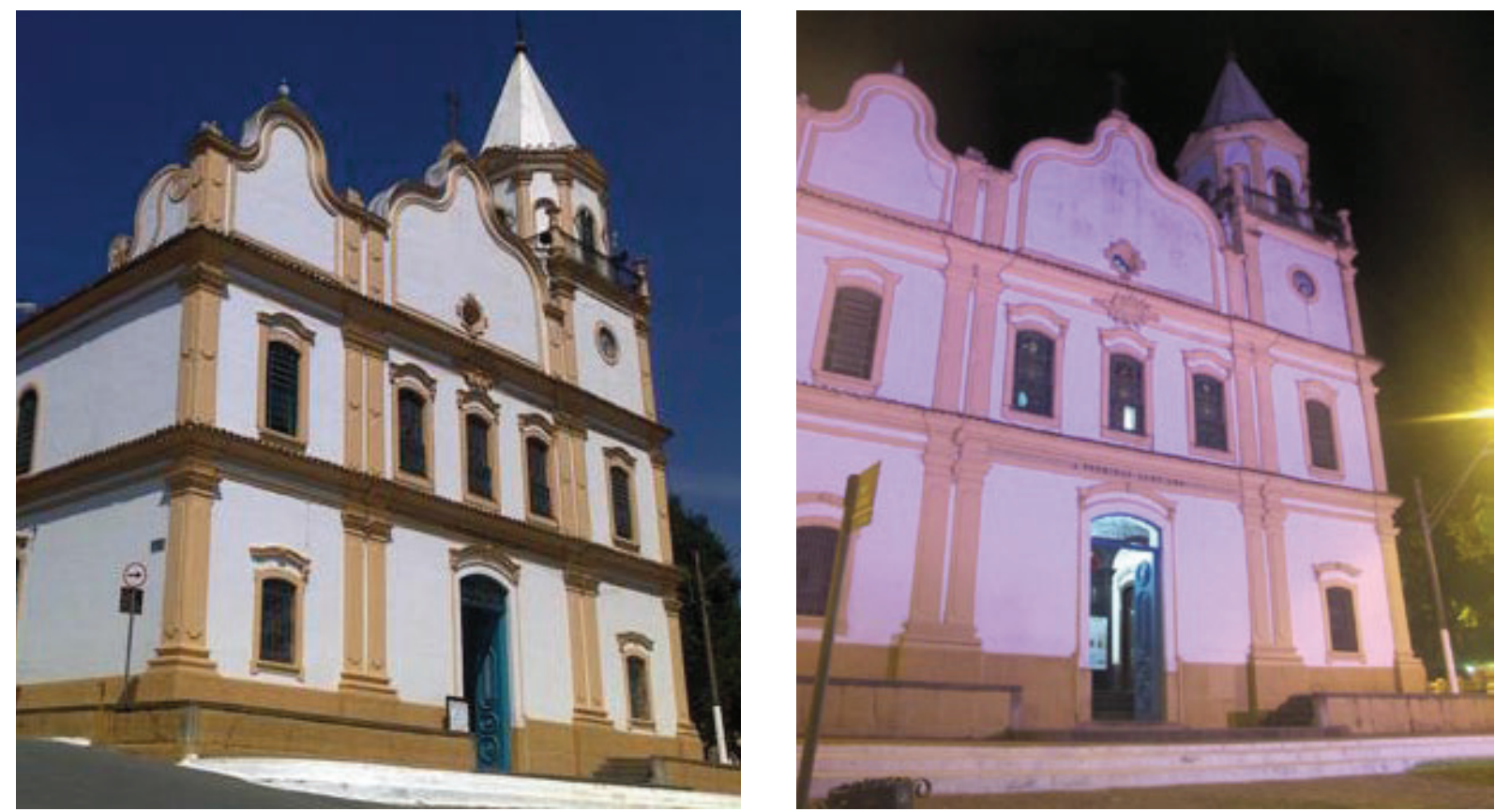

Figuras 18 e 19: Igreja Matriz de Santa Ana em Santana de Parnaíba: a alteração das cores reais da Igreja com a iluminação noturna. Fonte: Fotografias da autora 

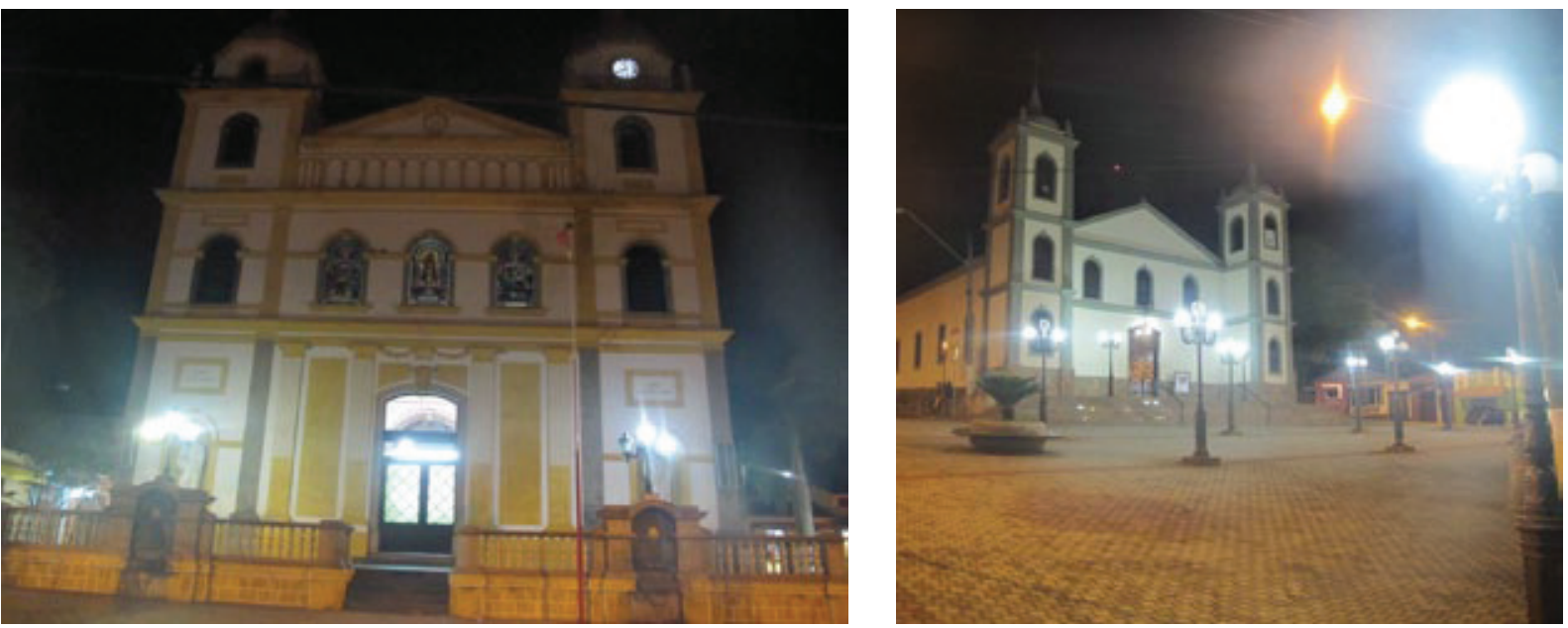

Figuras 20 e 21: Ausência de adequados projetos luminotécnicos para valorização noturna das Igrejas de Pirapora do Bom Jesus e Cabreúva. Fonte: Fotografias da autora.
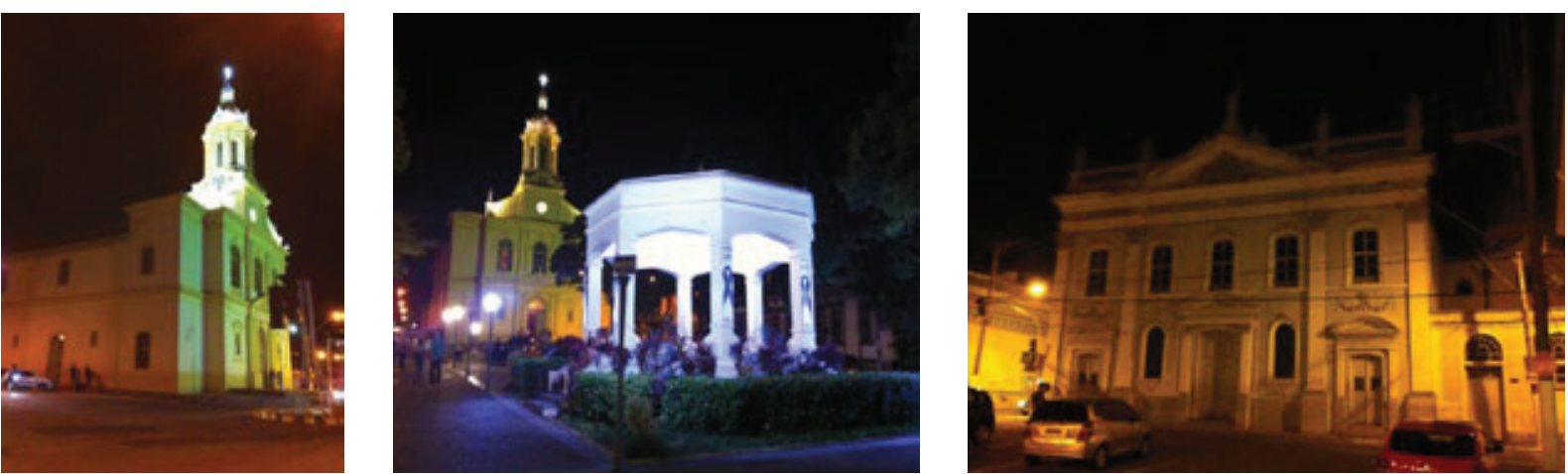

Figuras 22, 23 e 24: O excesso de iluminação versus a ausência de valorização noturna das Igrejas Matriz e do Bom Jesus, ambas na cidade de Itú. Fonte: Fotografias da autora

No que concerne os estabelecimentos comerciais, muitos sobressaem indevidamente, à noite, devido aos elevados níveis de iluminância que emanam do seu interior, transformando-se em espaços extremamente poluentes e ofuscantes do ponto de vista lumínico, para os transeuntes e condutores.
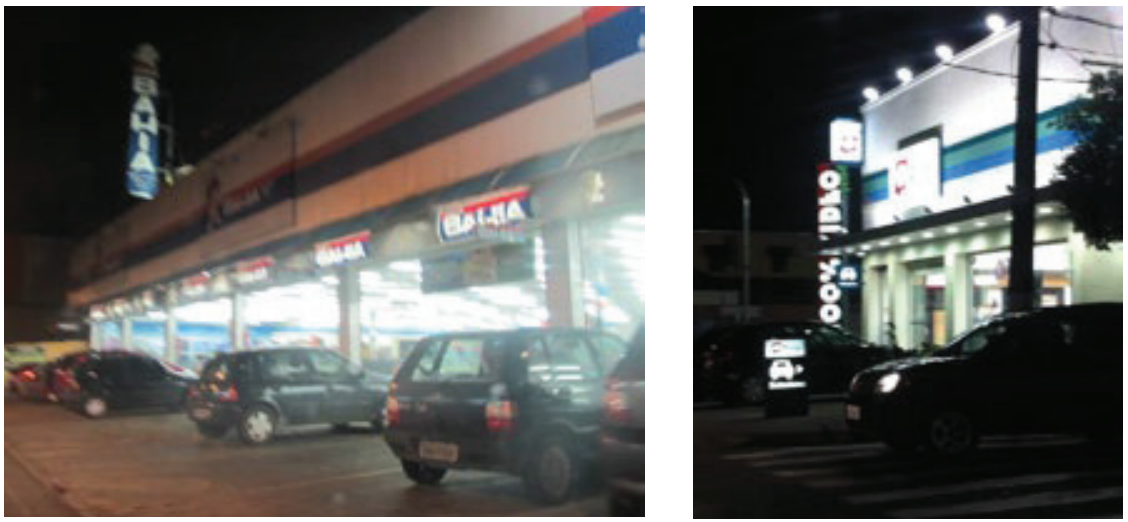

Figuras 25 e 26: Fenómeno de luz ofuscante proveniente de estabelecimentos comerciais, à noite, em Santana do Parnaíba e Itú. Fonte; Fotografias da autora. 
Por fim, muitos dos espaços verdes iluminados também padecem de adequada iluminação, sendo alvo de projetos onde luminárias ofuscantes e geralmente com filtros verdes acabam por deturpar a verdadeira expressão paisagística dos mesmos ou ofuscar quem decide fazer um passeio noturno por estes espaços. Como fenómeno agravante, sabe-se que a radiação térmica produzida por luminárias colocadas muito perto da folhagem pode, nalguns casos, gerar um aquecimento temporário capaz de modificar o seu desenvolvimento. ${ }^{33}$
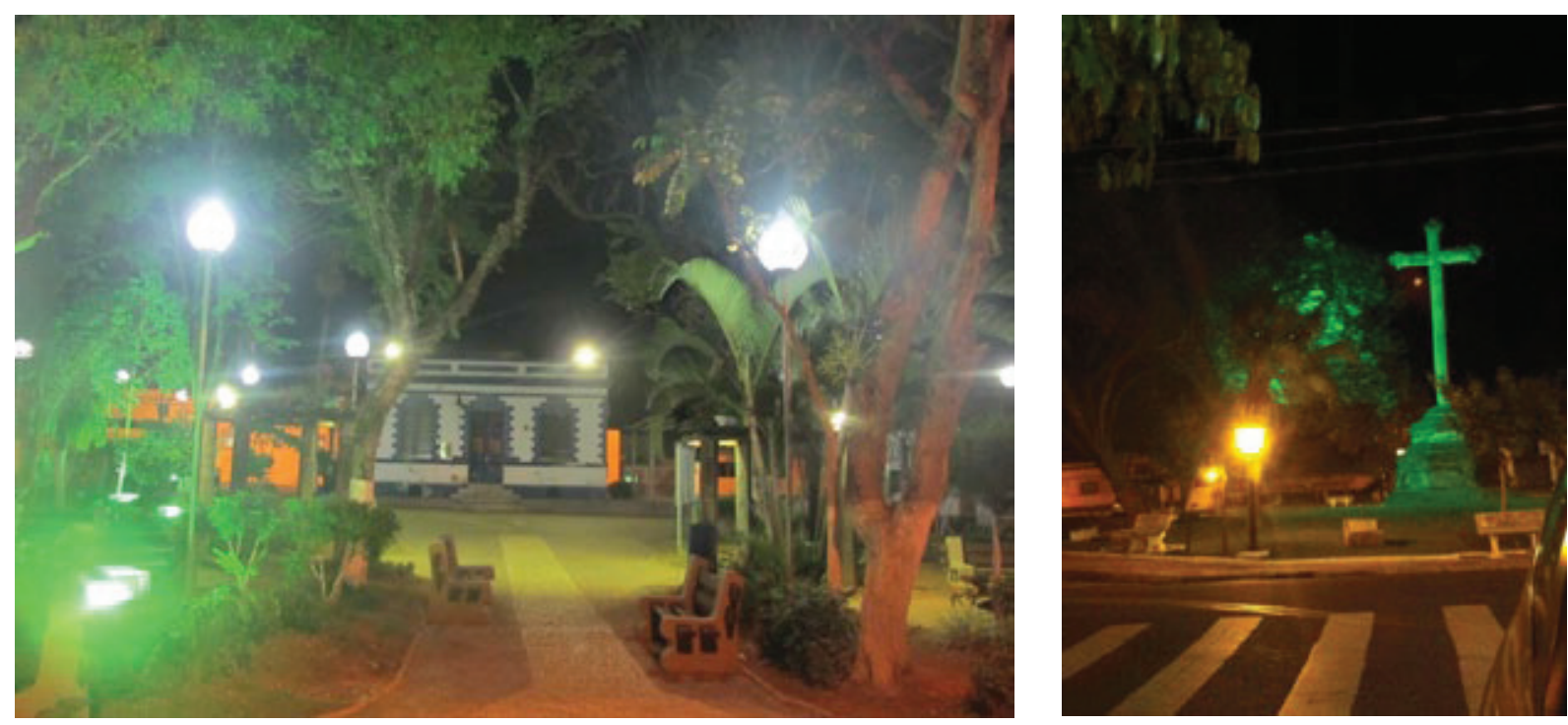

Figuras 27 e 28: Praças ajardinadas em Cabreúva e Itú: poluição luminosa, ofuscamento para os pedestres e luminárias com filtros verdes que deturpam a verdadeira aparência da paisagem. Fonte: Fotografias da autora.

\section{CONCLUSÃO}

A consciencialização para a pertinência da problemática luz artificial na sua relação com o espaço urbano é urgente. Os casos aqui apresentados não são únicos, mas antes representativos de uma realidade regional, nacional e mesmo mundial.

O estado de São Paulo, em virtude da forte densidade populacional e da acelerada expansão urbana que desde há um século não cessou de aumentar, apresenta uma notária precariedade e carência de reflexão na área da iluminação pública, essencial para a qualidade do espaço público, da segurança e do meio ambiente.

\footnotetext{
${ }^{33}$ Como a fotossíntese geralmente se produz na face superior da folhagem (que recebe luz do sol), as suas células são muito mais resistentes à radiação do que as que se encontram na face inferior da folhagem.
} 
Nos centros urbanos e via analisados, verifica-se ora insuficiência de níveis de iluminância onde eles são de extrema importância ou, em oposição, um excesso de luz que traduz pouca preocupação com questões como as de ofuscamento, poupança energética ou combate à poluição luminosa.

Onde a exigência de iluminação noturna é imprescindível, os níveis mínimos devem ser assegurados de forma a garantir a segurança, porém, a escolha dos equipamentos, a sua eficiência, durabilidade e interferência no espaço urbano e ambiental devem ser criteriosamente estudados.

Medidas como a simples substituição de lâmpadas obsoletas de forte consumo elétrico, a adequação de diferentes níveis de iluminação conforme os horários, o recurso a energias renováveis, etc., são soluções de extrema pertinência, porém não são suficientes.

O papel da iluminação enquanto instrumento de valorização das cidades e do património histórico que as compõe deve igualmente ser uma exigência nas cidades contemporâneas que no geral, tal como se viu nos casos analisados, padecem de projetos conscientes, executados por profissionais qualificados e com visão estratégica na área em questão.

Então, como forma de ultrapassar e evitar os problemas apontados, torna-se imprescindível que o estado e as entidades governamentais adotem medidas regulamentares como a implementação de planos diretores de iluminação.

Através deste método, já desenvolvido por várias metrópoles internacionais, tornase possível controlar, ordenar e harmonizar o sistema de iluminação de uma cidade ou região.

As características físicas da luz artificial e os respetivos efeitos luminosos dependem de inúmeros fatores, a maior parte controláveis: escolha da lâmpada (tipo, temperatura de cor, grau de restituição cromática, etc.); altura e orientação do equipamento; tipo de facho, regulável através de refletores, lentes ou da própria lâmpada; tipo de superfície iluminada; luminância presente na envolvente; etc.

Mas, para que um determinado espaço ou edifício receba as características de luz adequadas para a sua forma e função, é essencial que seja realizado um estudo criterioso e sob orientação de parâmetros gerais. 
Assim, como maior desafio, um plano diretor de iluminação deve conquistar, por um lado, uma integração da malha urbana, criando um fio condutor que a regularize e valorize no período noturno e, por outro lado, um reforço da especificidade de cada cidade ou local, evidenciando a sua identidade e características únicas.

No caso da iluminação de um edifício histórico, por exemplo, aquela não deve divorciar radicalmente o monumento da envolvente. Ou seja, a luz deve deixar prevalecer a supremacia hierarquia do edificado, mas este não deve deixar de se inserir em toda uma rede de iluminação equilibrada do resto da cidade, permitindo a leitura de todo o contexto urbano envolvente.

Ao envolver aspetos económicos, sociais, psicológicos e ambientais, intrinsecamente relacionados com a questão da iluminação, tornam-se necessárias decisões pluridisciplinares e de eco-cidadania.

A interdisciplinaridade representa um dos parâmetros fundamentais para o bom resultado de um plano diretor de iluminação, que necessita do envolvimento e diálogo entre intervenientes de áreas distintas. Só com a experiência, o conhecimento e o ponto de vista de diferentes profissionais como urbanistas, ecologistas, astrónomos, juristas, engenheiros e lighting designers haverá real sucesso no resultado. A independência dos intervenientes face a fornecedores e fabricantes de luminárias garantindo a honestidade projetual dos seus trabalhos torna-se um detalhe importante, para que aqueles concebam os projetos sem qualquer interesse comercial em termos de quantidade de equipamento.

Em suma, o presente artigo ambicionou alertar o leitor para a urgência na consciencialização da importância da luz em transformar, positiva ou negativamente, as nossas cidades. O trecho geográfico abordado serviu como exemplo para o atual estado da iluminação pública na maior parte das cidades brasileiras que, como se demonstrou, têm de ser alvo de profunda revisão, atendendo aos inúmeros aspetos evocados, que abarcam tanto questões sociais, culturais e urbanas, como ambientais, de sustentabilidade e eco-cidadania. 


\section{REFERÊNCIAS}

ANPCEN (Association Nationale pour la Protection du Ciel et de l'Environnement Nocturnes), "Dossier : La pollution Lumineuse", 01.08.07, in www.jourdelanuit.fr/IMG/pdf/ Dossier_ANPCEN_poll_lumineuse-2.pdf

BOGAERT, Jean Charles, "A luz, nova fonte de poluição", in Revista do Grupo Schréder, n 31, Lisboa, 2005.

COLOMBO, Silas, "Sem luz no fim do túnel" in revista Veja São Paulo, Ano 46, n² 29 , 17.07.13, Editora Abril, São Paulo.

ELETROPAULO - Eletricidade de São Paulo. Superintendência de Comunicação. Departamento de Patrimônio Histórico, Evolução Urbana da Cidade de São Paulo. 1872-1945. Série Bibliografia 1, Eletropaulo, São Paulo, 1990.

ELETROPAULO, A Cidade da Light - 1899-1930: edição bilingue portaguês-inglês comemorativa dos 5.000.000 de ligações / The City of the Light Company - 1899-1930: bilingual edition portuguese-english 5.000 .000 consumers commemorative /, Vol. I, Eletropaulo, São Paulo, 1990.

Jornal "República”, n 469, Itú, 25 de Janeiro de 1906.

LARSON, Leslie, Lighting and its design, Whitney Librairy of Design, Nova lorque, 1964.

LOVINS, Amory B. e Rocky Mountain Instltúte, Reinventando o Fogo. Soluções ousadas de negócios na era da energia", Editora Cultrix, São Paulo, 2013.

NARBONI, Roger, "Brève histoire de l'urbanisme lumière", in Penser la ville par la lumière, direcção de MASBOUNGI, Ariella, Éditions de la Villette, Paris, 2003.

NARBONI, Roger, Lighting the Landscape: Art, Design, Technologies. Birkhauser, Boston, 2004.

NARBONI, Roger, Lumière et ambiances: concevoir des éclairages pour l'architecture et la ville, Le Moniteur, Paris, 2006. 